\title{
MUEBLES Y ENSERES AL SERVICIO DE LA IMAGEN: EL TEATRO DE LA APARIENCIA DOMÉSTICA EN LA CATALUÑA DEL 1700 FURNITURE AND FURNISHINGS TO SHOW THE PERFECT IMAGE: DOMESTIC DECORATION IN CATALONIA IN 1700
}

Rosa M. Creixell Cabeza* Universidad de Barcelona

\section{Resumen}

A partir de las tramas más públicas de la cotidianidad, así como de las prácticas más particulares de aquello público, la aristocracia catalana del siglo XVIII perfiló como el resto de Europa nuevas maneras de mostrarse y presentarse al mundo. La creación de una máscara lujosa tuvo en la ornamentación de las arquitecturas habitadas el marco adecuado para construir una escenografía perfecta. Arquitecturas particulares, percibidas siempre como espacios ocupados en constante evolución, como reflejo de personalidades, gustos y modas de una época determinada, como escenarios poliédricos de acciones, deberes, deseos y funciones, en definitiva como "obra compuesta". Imágenes de ornato y atrezzo, donde vestir el cuerpo, descubrir los tempos en el ejercicio de las relaciones y pasearse por los espacios amueblados configuran los verdaderos vertebradores de una correcta geografía del habitar.

Palabras clave: Mueble, lujo, pragmáticas, domesticidad, siglo XVIII.

\begin{abstract}
Building on the most public aspects of daily life, as well as on the most private practices in the public arena, the 18th-century catalan aristocracy, like that of the rest of Europe, shaped new ways of showing itself and presenting itself to the world. The creation of a lavish masque had in the arrangement of inhabited architectures the ideal circumstances to build a perfect stage set. Private architectures, always perceived as constantly-evolving occupied spaces, as a reflection of the personalities, tastes and fashions of a particular period, as multifaceted scenarios for actions, duties, desires and functions: in short a "composed work". Images of ornato and atrezzo, where dressing the body, discovering tempos in the exercise of relations and strolling through furnished spaces are the backbone of an accomplished geography of inhabitation.
\end{abstract}

Keywords: Furniture, luxury, domesticity, "pragmática", eighteenth century.

\footnotetext{
"E-mail: creixellrosa@gmail.com
} 
"El mundo siempre vive engañado por el ornamento". W. Shakespeare. El mercader de Venecia.

\section{Introducción}

En el deseo de cualquier individuo de ser visto de una determinada manera- con admiración, temor, ternura, respeto, devoción o cualquiera de los muchos adjetivos posibles - juega un papel fundamental la construcción, consciente o inconsciente, que se hace de la propia imagen. Aun así, en la primera mitad del siglo XVIII, la apariencia individual se hallaba fuertemente arraigada a la imagen familiar. En esta "composición" de diferenciación o aproximación al resto de los miembros en que se inscriben las relaciones cotidianas, el individuo y muy especialmente la familia, concebida como elemento de transmisión del linaje, tiene en los actos de vestir el cuerpo y acondicionar sus viviendas una herramienta de gran utilidad para proyectar escogidas impresiones. La casa y el cuerpo, aspecto este último que no abordaremos en el presente artículo, toman una carga simbólica fundamental, puesto que acontecen imágenes calladas que nos revelan las maneras de estar y posicionarse de sus moradores. Espacios de observación y de acción, de distinción y también de diferenciación, (Fig.1) donde el lujo jugaba un papel esencial que las pragmáticas no pudieron frenar ${ }^{1}$.

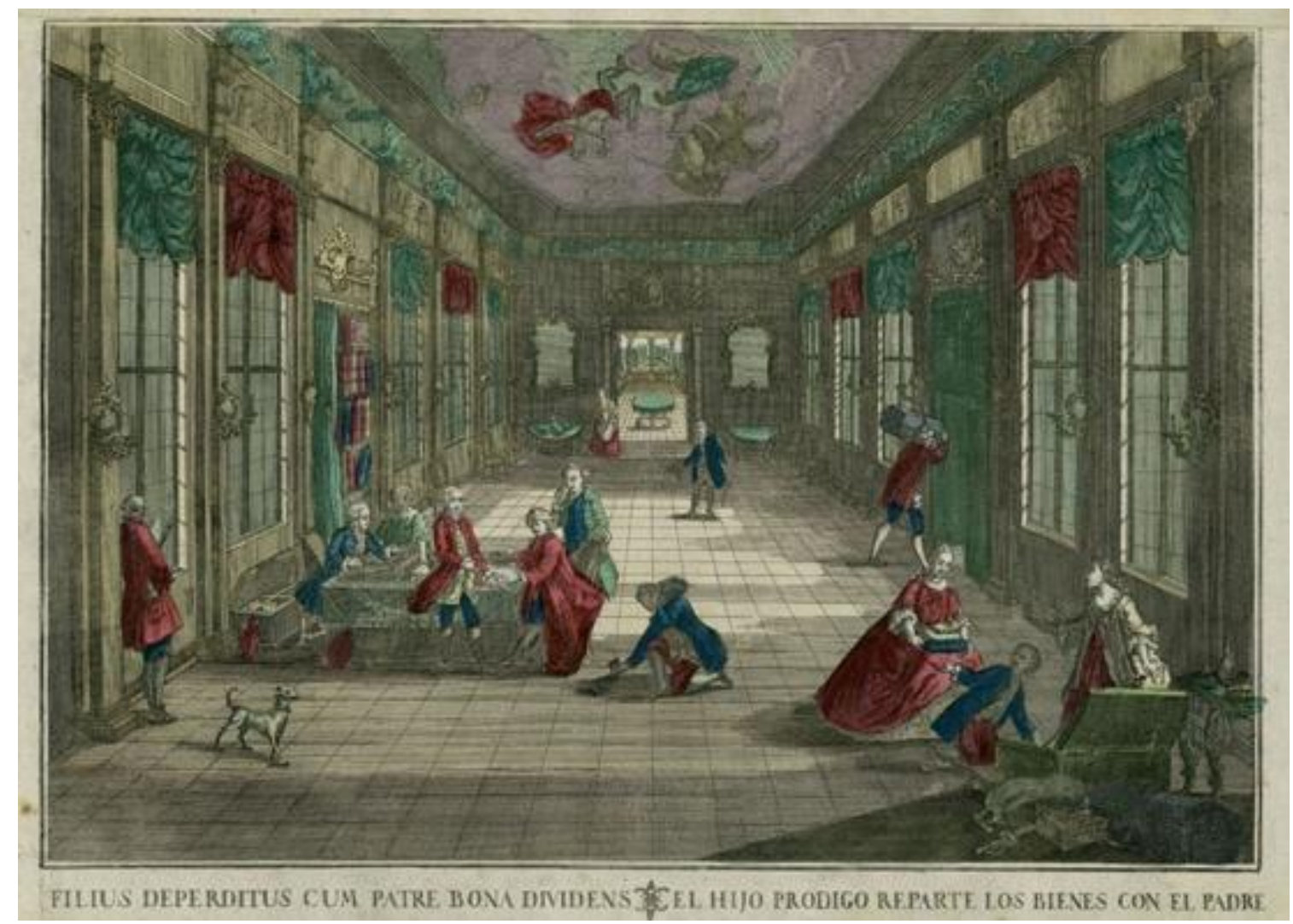

Fig. 1. El hijo prodigo reparte los bienes con el padre. Colección particular. 


\section{Las pragmáticas contra el lujo. Una herramienta ineficaz.}

El lujo o la suntuosidad en los artefactos empleados en la vida cotidiana servían para marcar distinción ${ }^{2}$. Por este motivo, los monarcas fueron receptivos a dictar pragmáticas contra el lujo justificándolo en la necesidad de combatir los desórdenes y los daños irreparables que podía comportar en los patrimonios familiares unos excesivos gastos. Reflexionar sobre el asunto no es baladí puesto que en el fondo de la cuestión subyace una voluntad de diferenciación clara de clase y jerarquización social por parte de la Corona respecto al brazo noble. Las primeras disposiciones en contra del lujo se remontan al reinado de Alfonso X y siguieron, con más o menos éxito, hasta finales del siglo XVIII. Centrándonos exclusivamente en el setecientos, el reinado de Fernando VI fue el único momento en trescientos años en que no se expidió ninguna ley al respecto. Juan Sempere, décadas después, se preguntaba en su obra Historia del luxo y de la leyes suntuarias en España ${ }^{3}$ por las razones de este hecho, que calificaba de inusual, mientras intentaba dar respuesta a dichos interrogantes. Para el jurista, bibliógrafo y economista algunos de los elementos que explicarían la carencia de prohibiciones durante el reinado de este Borbón era el desmesurado gusto de la reina consorte por los objetos suntuosos, aspecto al que se le sumaría la tarea desarrollada por sus ministros para incentivar una floreciente industria donde la creación de fábricas destinadas a producir artefactos lujosos se consideraba un motor esencial para el desarrollo del país. Intereses muy distintos a los que se dieron en el reinado de su padre, Felipe V, puesto que dicho monarca restauró determinadas leyes suntuarias dictadas por sus antecesores, especialmente las decretadas por Felipe II, creando otras nuevas que fueron apareciendo en sucesivos bandos gubernamentales. La primera en el año 1723, con algunas modificaciones al año siguiente, y siendo reeditada en 1729. Las normas que establecía se centraban en los asuntos del vestir, en el privilegio de poder poseer un coche, determinar el número de criados posibles y prescribir como tenían que ser las dotes de boda así como los lutos por la muerte de un familiar. Normas y prohibiciones que no surgieron efecto, pues las pragmáticas no pararon los excesos en el boato, según recoge Sempere en su obra. El autor indicaba que al cabo de poco tiempo ya no eran observadas porque el deseo de poseer cosas costosas y exóticas, es decir, lujosas, es inherente a la condición humana. Más tarde, Carlos III decretó otras prohibiciones. En marzo del año 1766, un bando establecía la prohibición del uso del vestido con capa larga y la introducción de las teles de muselina en el país. Finalmente, en noviembre de 1783 se volvió a recordar como tenían que ir guarnecidos los carruajes, o coches, indicando los caballos, mulas y criados que podían traer. Curiosamente, también fue en este momento cuando apareció el primer veto en contra de la celebración de fiestas taurinas, de arraigada tradición entre la nobleza.

La lectura atenta de las pragmáticas nos revela una constante atención sobre determinados productos y artefactos. En primer lugar hay un control férreo sobre la indumentaria, especialmente con los vestidos ornamentados con hilos de oro y plata. Así, mediante una pragmática firmada en 1593 se prohibió cualquier 
ornamento hecho con estos materiales en los puños, cuellos y en otras partes de las camisas, salvo que fueran exclusivamente de color blanco. La ley fue renovada en los años 1600 y 1611, aunque con algunas matizaciones. Por ejemplo, en la primera reedición quedaba claro que esta normativa no afectaba a los miembros de la monarquía, a los religiosos ni algunos militares, como tampoco a los que contaran ya con este tipo de vestido en su ajuar, dándoles cuatro años para usarlos en el caso de los hombres, plazo que alargaba a seis en el caso de las mujeres. Dos años más tarde quedaba sin efecto dicha disposición.

Además de los vestidos, el mobiliario y el arreglo de la casa también fueron un motivo de atención constante, aunque en menor grado. A finales del siglo XVI y a principios del XVII se condenaba la realización y la venta de piezas de plata, citándose explícitamente las tipologías de bufetes, escritorios, arquillas, braseros, contadores, sin olvidar todo tipo de imágenes y obras guarnecidas con plata. En realidad, es justo indicar que en el caso de los muebles, habitualmente, se hacía referencia casi exclusivamente al tipo de telas que los vestían. En el siglo XVIII, una vez más, las leyes se centran en las ropas, los coches y los criados siendo escasa o casi nula la atención al mobiliario y la decoración de la casa.

La discusión de si el lujo era necesario y útil a las naciones fue una de las cuestiones más debatidas a lo largo de toda la segunda mitad del setecientos. En Cataluña uno de los autores que destacó y trató dicho asunto en sus obras fue Francisco Romà y Rossell en Las senyales de la felicidad4, escrita en 1768. Para él, dar una respuesta sincera y veraz solo era posible si el tema no era tratado de forma general, puesto que defendía la existencia de distintas categorías posibles donde incluir el lujo, afirmando de la misma forma que cada país daba un contenido distinto a dicho concepto. Partiendo de estas dos premisas era comprensible que la utilidad o no del lujo dependiera directamente del uso que le daba cada sociedad. La implantación y disfrute del lujo sin normas, al servicio de la voluptuosidad, era para Romà y Rossell perjudicial, pero defendía el que nacía del deseo de tener una casa bien puesta, de presentarse delante de los otros correctamente vestido, o de mejorar en la escala social a partir del uso correcto y útil de los artefactos suntuosos. Por esta razón, el autor defendía la necesidad de una industria del lujo para la nación española pues entendía que además de suponer el sustento de las familias menestrales, también activaría la economía y el comercio. En realidad esta idea no fue exclusiva de Romà y Rossell, puesto que, expresándolo en términos opuestos, Sempere y Guarinos, a finales del siglo XVIII, defendió teorías similares. Este último, advertía en sus escritos de lo dañino de unas leyes fundamentadas en la ignorancia y el desconocimiento de la realidad. Para él, promulgar leyes inútiles o desacordes al lujo, tenía como consecuencia el efecto contrario, dejando claro que aunque cierto que los excesos en una sociedad podía acelerar la ruina de un estado, este vicio no era la causa real de los males de una nación. Convencido estaba de que para el bien de las artes, la industria y el comercio, era necesario y crucial estimular el consumo de artefactos lujosos, puesto que: 
“(...) sin consumos no hay despacho en los géneros. Sin despacho les falta a los artistas la paga de su trabajo: se fastidian de un exercicio que no les da con que subsistir, y mantener las obligaciones respectivas: dexan los oficios, y se abandonan a la ociosidad, la indolencia, la poltronería, y la mendicidad, vicios por lo menos tan malos, y perjudiciales como el mismo luxo y los que de él resultan. Es más (...) de todos ellos pueden ser causas parciales, e indirectas las Leyes suntuarias, contra la intención de los soberanos que las expiden, y de los magistrados que las consultan". Y la razón no era otra "porque prohibiendo el uso de algunos géneros comerciables, y mucho más si se fabrican en el país, disminuyen el número de ocupaciones útiles, y lucrativas, con las que los pobres pueden vivir cómoda, y honradamente; circunscriben los límites a que pueden extenderse la industria, y el ingenio; y amortiguan el estímulo más fuerte del trabajo, que consiste en la esperanza del buen despacho, y paga de las manufacturas"5.

Así pues los dos intelectuales coincidían en considerar y calificar las pragmáticas como disposiciones perjudiciales para el correcto desarrollo de la industria del país. La solución radicaba, especialmente para Romà y Rossell, en ser cautos en los dispendios, en mantener siempre una buena administración en la economía y los patrimonios. No se trataba de renunciar a mostrarse con vestidos elegantes o descuidar el ornamento de forma esplendorosa de las habitaciones, si no de evitar ser desmesurados con gastos inútiles.

Uno de los motivos, especialmente en los siglos XVI y XVII, que justificarían la proliferación de leyes suntuarias por parte del Estado radicaría en los constantes cambios de moda que se acontecían. La poca duración de éstas en el marco de una sociedad de estricta etiqueta era percibida como un elemento de desestabilización, que llevaba a trastocar el sentido de la misma sociedad. En el siglo XVIII el foco de atención estará en la lucha de clases y jerarquías. En este sentido Sempere hace suyas las palabras de autores del pasado que explicitaban de manera contundente dichas cuestiones en los siguientes términos:

\footnotetext{
"aunque el daño (dice) de hacerse costosos vestidos es tan grande, es mayor el de la mutabilidad de los usos, no haviendo en los españoles trage fixo, que dure un año (...). En los edificios se nota que las casas, que sesenta años antes se juzgaban por suficientes para un grande, las desechaban por pequeñas personas de muy inferior gerarquía: y que las mugeres de los oficiales mecánicos tenían en las suyas mejores alhajadas, y mas costosos estrados, que poca antes las de los títulos (...). Tampoco se contentan ya los hidalgos particulares con las colgaduras, que pocos años antes adornaban las casas de los Príncipes"6.
} 
Es interesante indicar que no sólo la producción de artefactos lujosos estuvo regulada por pragmáticas reales que favorecían la moderación en su uso, sino que incluso determinados ceremoniales fueron estipulados por la ley. En concreto, el ceremonial de la muerte así como las dotes matrimoniales sufrieron un intento de regulación infructuoso, en el empeño del gobierno de atajar con una de las causas del hundimiento de más de un distinguido patrimonio familiar. (Fig.2) La pragmática de 1723 y su reedición de 1729 recogen, pues, las ideas y sugerencias que ya se estipulaban en las dictadas por Carlos V y Felipe II en torno a dicha problemática. La intención era conseguir de la población, y especialmente de la aristocracia, una respuesta según las posibilidades reales, económicamente hablando, de los patrimonios familiares implicados en las alianzas matrimoniales. De esta manera se pretendían evitar desórdenes y daños irreparables. La solución propuesta no fue otra que estipular un baremo de cálculo según la cuantía del patrimonio de aquellos que se veían en trámite de dotar un hijo o una hija, aun de recomendar que no se hicieran regalos de boda y, si esto era inevitable, que el valor crematístico no superara la octava parte de la dote. En esta misma línea, en 1623 Felipe IV, y como ejemplo para el pueblo, mandó moderación en las bodas de los miembros de la realeza y estableció un ceremonial a seguir que intentaba evitar en la medida de lo posible los excesos. Se debe indicar que, pese a ser conocidas estas disposiciones, los miembros de la nobleza barcelonesa hicieron caso omiso si consideramos el valor y suntuosidad de sus pertenecías, así como la riqueza con que se desarrollaron sus fastos.

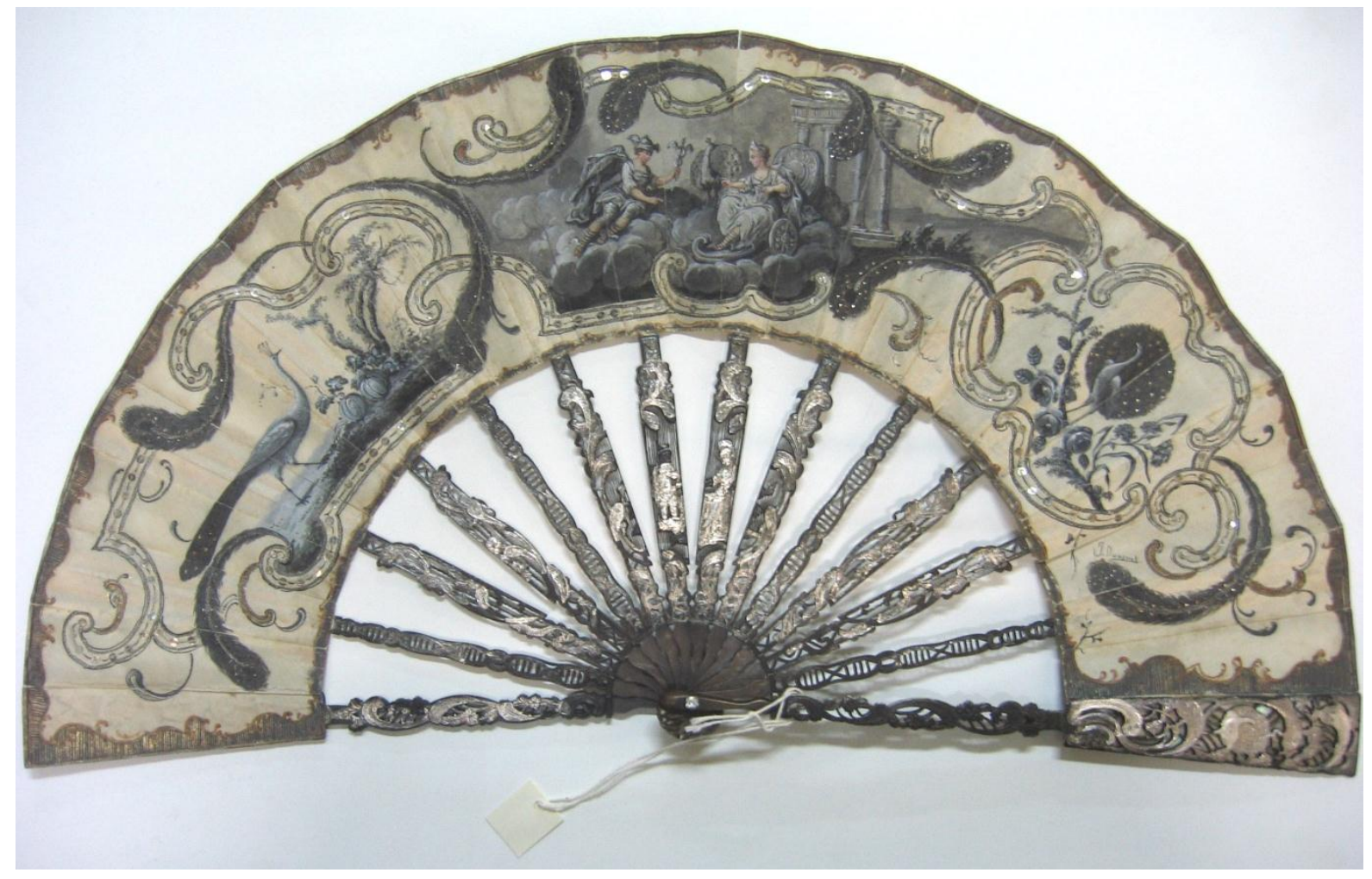

Fig. 2. Abanico de luto. Manufactura francesa. Museu del Disseny de Barcelona. 
No podemos dejar de mencionar que, al igual que con las bodas, las pragmáticas intentaron regularizar los excesos de suntuosidad respecto a las pompas fúnebres y el duelo. Felipe $\mathrm{V}$, en la misma pragmática, recogiendo lo que ya había sido establecido en la de 1691, ordenaba que todo el mundo tenía que vestir de negro y establecía los tejidos que se podían emplear según fuera verano o invierno. Lógicamente, detrás de esta prohibición uno puede ver una evidente voluntad de diferenciación que la monarquía perseguía respecto a los estamentos más beneficiados de la sociedad, tal y como ya hemos manifestado al principio de este apartado. Una normativa estricta que determinaba:

"que solo puedan traer luto las personas parientes del difunto en los grados próximos de consanguinidad, y afinidad, expressados en la misma ley, que son padre, ò madre, hermano, o hermana, abuelo, ó abuela, ó otro ascendiente, ó suegro, ó suegra, marido, ó muger del heredero, aunque no sea pariente del difunto, ni à los de sus hijos, yernos, hermanos, ni herederos; de suerte, que no se puedan poner lutos ningunas personas de la familia, aunque sean de escalera arriba"7.

La obsesión por intentar acabar con la desmesura llegaba incluso a marcar como debían ser los ataúdes o cajas, la decoración de las iglesias, la confección de túmulos o la misma casa vestida para tan triste ocasión. Respecto a la sepultura del difunto, en la caja no podían emplearse sedas o telas finas de colores, y sólo se permitía el morado o el negro, reforzando en la convención social que los colores llamativos no eran adecuados en un momento de gran tristeza. Sólo estaba permitido contradecir esta norma si el fallecido era un niño.

Así pues, y a pesar de las pragmáticas, lo cierto es que los elementos suntuosos estuvieron al servicio del retrato que cada individuo quería dar de sí mismo. La construcción de esta imagen particular, que a la vez debe responder al espíritu de la época, vendrá orquestada por las normas más estrictas de la etiqueta. Por tanto, en la representación de la propia vida se vigilará todos los aspectos pertinentes que permitan lucirse ante los demás miembros de su clase. No es casual la atención que se dará a las viviendas y a su acondicionamiento, pues será concebida como un pequeño teatro. La casa era la esfera de acción doméstica donde transcurren gran parte de los acontecimientos importantes. Es un elemento a tener en consideración para mostrar el correcto juego de la sociabilidad que se produce en este mundo complejo provisto de un lenguaje particular y propio.

\section{Fragmentos de la escenografía doméstica en los interiores aristocráticos de la ciudad}

A pesar de las ordenanzas establecidas, en el acto de habitar una casa gran $^{8}$ la nobleza distribuía sus espacios en estancias de apariencia majestuosa, 
donde representar un rol social, y en otros más simples, reducto de privacidad. Una primera frontera entre estos dos tipos de escenarios que convivían en un mismo hogar aristocrático venía dada por su propia ubicación en diferentes plantas, ya que se reservaba la principal o noble a las actividades sociales y se disponían los pisos superiores para cámaras de uso particular, donde solía reinar un cierto desorden compositivo. (Fig. 3) Dada la gran cantidad de estancias que podía llegar a alcanzar una vivienda aristocrática, fue un hecho común que se las denominara con nombres que singularizan el espacio respecto al resto de cámaras de la casa, nombres que, por otra parte, solían hacer referencia a los artefactos o menaje rico que contenían y las distinguían del resto, como la sala de las escaparatas, o, incluso, al uso que de ellas se hacía, como el "cuarto de las mujeres" en el hogar de los condes de Múnter.

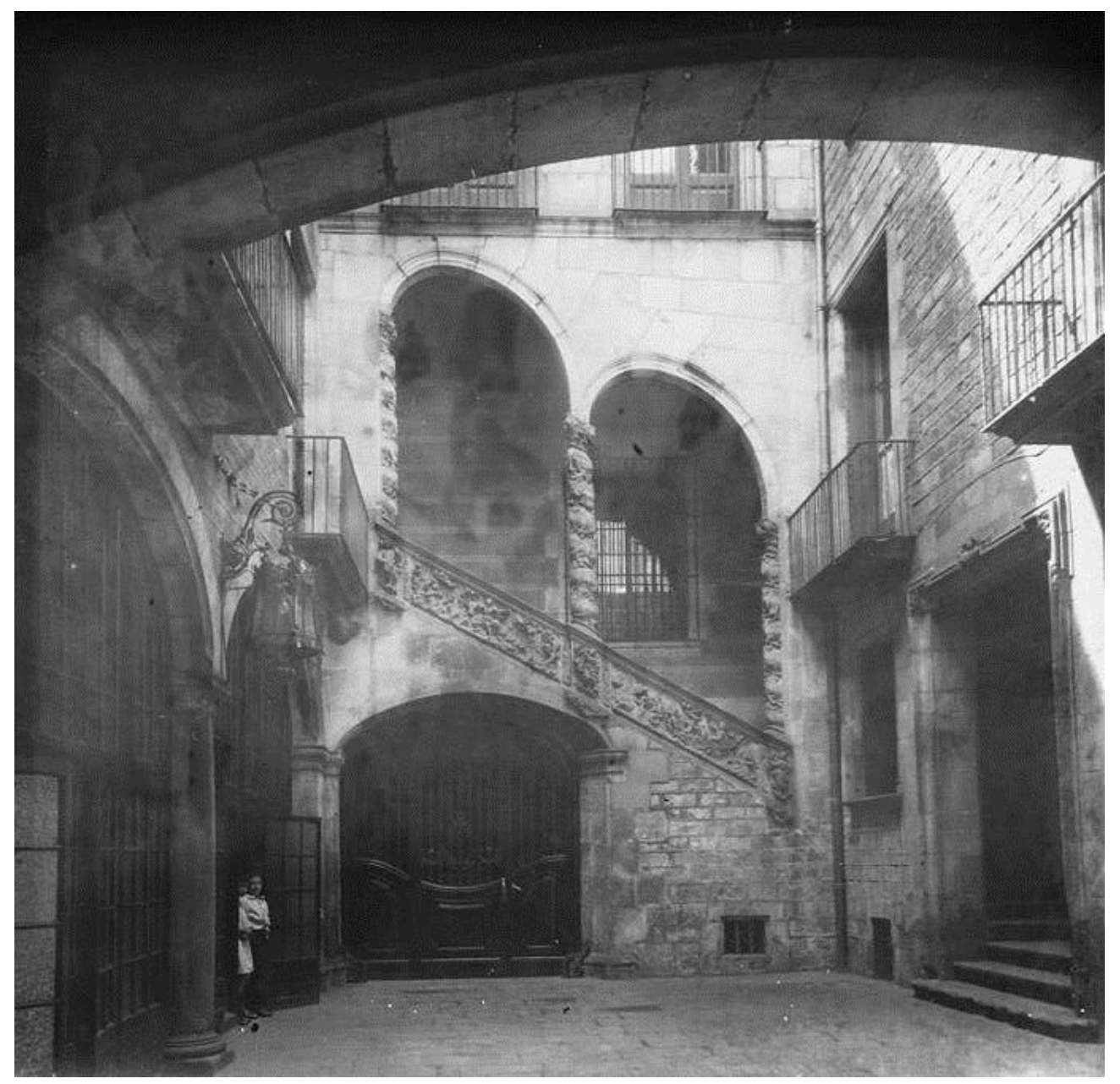

Fig. 3. Entrada de la casa gran de la noble familia Dalmases. Carrer Moncada, Barcelona, Biblioteca de Catalunya.

La escenografía doméstica, a diferencia de lo que sucederá en las residencias de la segunda mitad del siglo que optarán por programas pictóricos para ornamentar las estancias más importantes, aun se servirá del textil como elemento principal a lo largo de la primera mitad del setecientos. La confluencia de colores y objetos en una misma estancia se convierte en el rasgo idiosincrásico 
de cualquier sala, estrado o salón principal, desvelando un arraigado sentido del horror vacui en los gustos de la aristocracia local. En este sentido, si bien la gran cantidad de artefactos dispersos y heterogéneos que contenían las cámaras puede hacer pensar que no existía una especialización en los usos de las estancias, ya se trasluce una concepción y uso diferente del espacio por parte de los hombres y las mujeres del setecientos. En términos generales, se intuye una nueva manera de ocupar los espacios encaminada a un uso específico de cada habitación, aunque no puede hablarse de una total normalización. Un signo evidente de lo que se acaba de manifestar sería el incipiente traslado de las grandes camas paradas en salones, salas y estrados, hacia los habitáculos destinados para dormir.

Tendencia que pervive, de manera minoritaria en determinadas viviendas, donde la familia todavía prefería disponerlas como piezas de representatividad.

Entre el conjunto de salas que podía tener una casa gran destaca por su magnificencia y menaje opulento, por encima de todas ellas, el estrado que entraba en competencia directa con el salón y la sala gran. En el tomo IX, parte I, de la obra de Benito Bails, Elementos de Matemáticas ${ }^{9}$, se define esta habitación como una pieza destinada a acoger a mucha gente y en la que era del todo necesaria la existencia de muchos asientos. Aconsejaba también, que, además de una buena iluminación, fuera dispuesta entre el comedor y el jardín, aspecto que indica una secuencia de actividades que comenzaba con el banquete, continuaba con la conversación en el estrado y terminaba con el paseo por el jardín. Lo que más interesa destacar es su función como sala de reunión, donde la actividad principal era la conversación, en contraposición a la sala gran- siempre según las informaciones de Bails-, que servía para jugar, escuchar música $u$ ofrecer refrescos a los amigos. La cantidad de estrados podía variar en función de la importancia del hogar, pero muy a menudo podían llegar hasta tres, aspecto que evidencia la pervivencia de los dispositivos y las costumbres del pasado en la organización del espacio. Siguiendo la lógica de antaño, el primer estrado hacía de recibidor, es decir de primer filtro de aceptación a la morada. Los restantes estrados se caracterizaban por tener una superficie considerable y presentar una gran cantidad de asientos para dar cabida a los visitantes, amigos y familiares que habían superado la frontera del recibidor, los cuales eran dignos de acceder a un grado más de la intimidad de los propietarios o anfitriones. Es importante indicar, que en las mansiones aristocráticas barcelonesas, a pesar de la pervivencia del estrado, cada vez fue más habitual la aparición de salas y salitas como punto de reunión, y del salón como el escenario principal de la representatividad social donde pasar el tiempo con bailes y saraos.

\section{La geografía de la adquisición: La compra de mobiliario en mercados extranjeros y talleres locales.}

En esta escenografía doméstica de la apariencia, la demanda de objetos suntuosos por parte de determinados sectores de la sociedad barcelonesa, donde además de la nobleza cabe destacar una nueva clase emergente deseosa de emular las maneras de hacer de los estamentos más prestigiosos, habría supuesto 
el desarrollo de una intensa actividad comercial. En este sentido se puede afirmar que el comercio exterior entre Barcelona y otros lugares gozaba de una excelente salud. Un recorrido por las diferentes cámaras de una casa aristocrática barcelonesa deja intuir el gusto, la curiosidad y la apertura de sus inquilinos respecto a los modelos y las costumbres del resto de Europa. No está de más recordar, por ejemplo, que a partir del siglo XVI la ciudad de Barcelona mantuvo un intenso tráfico comercial con puertos italianos, portugueses, flamencos, orientales y de las Indias, lo que propició sin lugar a dudas un activo intercambio de productos, donde quisiéramos remarcar el del mobiliario que procedía de Italia, Francia y Moscú10. A grandes rasgos podemos establecer que los objetos lujosos traídos del extranjero para vestir estancias y adornar los cuerpos procedían de compañías que operaban en los principales puertos mediterráneos. Marsella, Génova, Nápoles y la isla de Malta, principalmente, aunque hay que citar también el contacto comercial con el mercado africano de Orán y hay que sumar una segunda ruta que establecía el eje comercial entre Barcelona y los puertos portugueses, ingleses y de los Países Bajos y holandeses, desde donde también sería factible el comercio más allá del Atlántico.

En las dos rutas, especialmente en el caso holandés y en el italiano, los textiles sin obrar destinados a vestir los interiores o confeccionar vestimenta de uso personal fueron los productos más importantes. Sin embargo, de Italia, no fueron los únicos productos, ya que también se adquirían cajas con sombreros, naipes, flores artificiales llamadas "fingidas", papel de escribir, confituras, medias y guantes de seda, bolas de mármol, abanicos, libros, peines de marfil y cajas de dulces. En determinados cargamentos aparecen consignados espejos con su correspondiente guarnición, los cuales podrían proceder de la ciudad veneciana de Murano. Todo, por supuesto, con sus respectivas marcas. Dos ciudades italianas que también fueron un mercado importante del comercio catalán de la época, aunque de segundo orden en comparación con Génova, fueron Livorno, en la zona de la Toscana, de donde se llevaban pañuelos de seda sencillos y dobles y Venecia. Los espejos venecianos eran una de las producciones dentro de los accesorios del amueblamiento más importante. Entre la gran variedad de modelos y de formas cabe destacar los espejos ornamentados en el marco con cristales de colores, técnica decorativa alternativa que se impuso en los talleres locales en sustitución de los realizados con madreperla y laca, que singularizar la ciudad de los canales.

Mientras que Venecia se especializaba, sin olvidar por ello su industria típica de confección de caretas o máscaras fastuosas, en el trabajo del vidrio y, por tanto, muchos agentes comerciales adquirían espejos y cornucopias en esta ciudad del Adriático, en Roma, se compraban básicamente cuadros y abanicos. La escasa información sobre las manufacturas romanas localizadas en la documentación, así como las pocas piezas consignadas en los interiores obliga a pensar que eran piezas que gozaban de una cierta calidad artística y tenían un precio elevado en el mercado. El cuadro de Roma que tenía el noble Anton de Sunyer ${ }^{11}$ representaba la imagen de la Anunciación y estaba situado en el altar de la capilla privada de su vivienda. De forma más esporádica, constatamos la llegada de muebles procedentes de la capital italiana como el de la noble dama 
María de Rocabertí12, que, además de dos láminas también procedentes de esta ciudad, muy finas y enmarcadas con un marco de madera de ébano y planchas floreadas de metal, tenía un canterano con cinco cajones grandes ${ }^{13}$. Destacar entre los muebles de más éxito procedentes de Italia las mesas consignadas como a la genovesa. Las descripciones localizadas permiten definirlas como una mesa que presentaba como característica principal su tablero de piedra de color negro. Cuando eran contrahechas, a la manera italiana, se empleaba piedra de Tortosa, y de ahí que se encuentren citadas en algunas ocasiones como "mesas de Tortosa".

Situándonos geográficamente hacia el sur, en las casas barcelonesas importantes también se encontraban muebles y artefactos suntuosos elaborados en los talleres napolitanos. En realidad, se debe hablar de una pervivencia de modelos del pasado, como eran los escritorios de vidrios pintados con motivos históricos, y una lenta introducción de nuevos objetos decorativos más a la moda. Entre ellos cabe destacar las figuras de pesebre que tuvieron en la segunda mitad de la centuria un gran éxito o los cuadros realizados con labor de bordadura, o los adornos florales hechos con seda para poner dentro de las escaparatas y capillas. Tampoco se pueden omitir los marcos de corladura para las pinturas, ni los espejos con corladura y dorados de diferentes tamaños. Sin embargo, la tipología originaria de Nápoles que más éxito tubo en todos los hogares catalanes del período fue la silla policromada con asiento de paja, tipología muy popular en toda el área mediterránea.

La impronta del mobiliario inglés dentro de las viviendas barceloneses y, especialmente, en las cases grans, fue considerable. El comercio con Inglaterra era un mercado importante si consideramos la cantidad de piezas, especialmente mobiliario, que son citadas "a la inglesa" en los inventarios postmortem de la aristocracia de la ciudad. (Fig. 4)

No debemos olvidar que la ruta comercial con los puertos ingleses estaba conectada con los holandeses. No es difícil suponer que los barcos procedentes del puerto de Ámsterdam hacían escala en los puertos ingleses, para repostar o para cargar y descargar más mercancías, tal y como sucedía en el puerto de Marsella para el área mediterránea. Aspecto que dificulta, en gran medida, saber con exactitud cuáles eran los lugares de origen de los productos que llegaban al puerto barcelonés. 


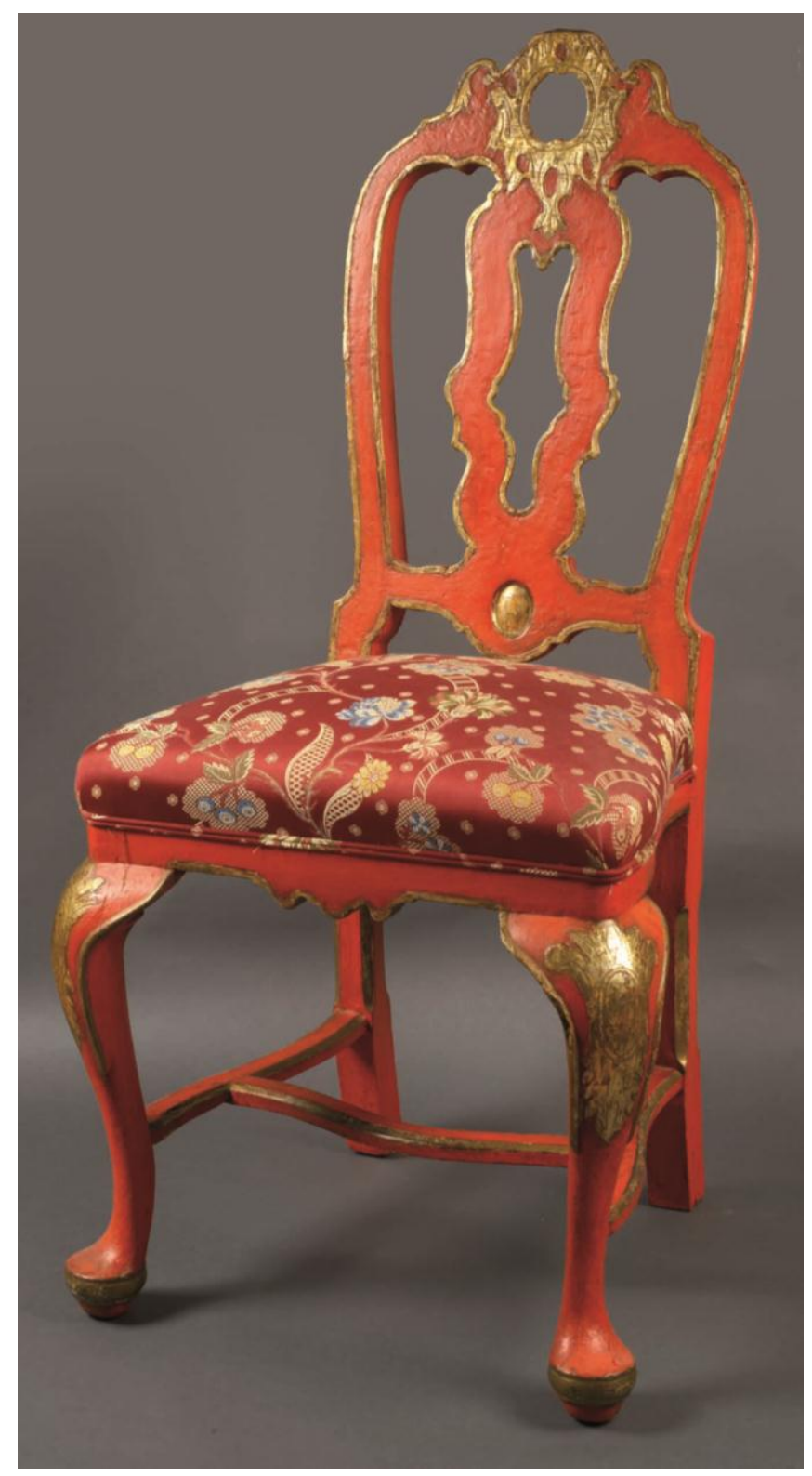

Fig. 4. Silla a la inglesa. Colección particular.

La existencia de un comercio con Inglaterra no puede ser puesto en duda si atendemos a los libros de cuentas de gente como Francisco Roig, platero que abandonó esta actividad para dedicarse al comercio de cereales con Holanda e Inglaterra. Entre sus facturas se hallan algunas pertenecientes a la adquisición de muebles ingleses y holandeses. A través de Francisco Palau, que actuaba como agente, compró un escritorio o tocador y un reloj de Inglaterra, además de una cómoda de Holanda por la boda de su hijo, entre la década de los años treinta y cuarenta del siglo XVIII ${ }^{14}$. A estas tipologías de muebles que acabamos de citar, debemos añadir gran cantidad de asientos procedentes de Inglaterra, así como un gran número de muebles lacados. 
Muebles lacados, que compitieron con las piezas procedentes de otras regiones. La introducción del mueble lacado en Europa penetró por diferentes vías. En este sentido hay que advertir que las compañías comerciales tuvieron un papel fundamental en la propagación del gusto oriental, abriendo el camino a lo exótico. La ruta atlántica, es decir Holanda e Inglaterra, fueron los proveedores de este tipo de mueble en los hogares aristocráticos catalanes. De procedencia holandesa eran los que tenía Anton Boet, prohombre del comercio de la ciudad. Otros fueron encargados a talleres barceloneses. De Holanda llegaron dos mesas de estrado de pintura azul, espejos, algunos dorados y otros de madera de nogal, una cómoda y un tocador de charol con flores doradas, así como tres armarios, uno de madera de nogal con seis cajones y dos de charol, es decir lacados ${ }^{15}$.

Dentro de los muebles lacados de procedencia holandesa cabe destacar diferentes modelos tipológicos de mesas, todas ellas de una gran artisticidad. Sebastián Vidal poseía una pareja de mesas donde se encontraban representadas las historias de la casta Susana y la del casto José ${ }^{16}$. El noble Francisco Bassols tenía dos mesas trabajadas en Holanda realizadas con pintura y barniz, que hay que suponer imitando las lacas, compradas pocos años antes de morir. Jaume Guardia, de la pequeña nobleza de ascendencia comercial, tenía dos mesas pintadas que también se consignan como holandesas. Indicar que las primeras referencias que empiezan a generalizarse sobre este tipo de mueble se encuentran en inventarios levantados en torno a la década de 1730, lo que permite apuntar que la moda se habría iniciado a principios de la centuria. A modo de ejemplo, el platero Francisco Roig, hizo traer de un viaje a Ámsterdam dos mesas rojas con partes doradas, así como una caja con lomo negro y las memorias de Lamberti ${ }^{17}$ dentro de ella; y el ciudadano Pedro Pérez en 1766 tenía dos mesas redondas de abanico de Holanda con figuras y barniz, es decir, según el gusto oriental 18 .

Dentro del menaje lujoso de una vivienda, por lo que respecta al mobiliario, se debe insistir en que el interés por el mueble lacado, en Europa hizo que a partir de mediados del siglo XVII muchos países encontraran la manera de acceder y producir artículos que imitaran las lacas. Los constantes intentos por conseguir unas lacas similares a las orientales, a un bajo coste y de una calidad similar, propiciaron el desarrollo de la laca povera en el ámbito italiano, piezas que tuvieron una gran acogida en el ámbito catalán. (Fig. 5) El proceso técnico con el que se fundamenta la decoración de cualquier artefacto doméstico realizado con laca povera consiste en aplicar a la superficie del mueble ornamentar estampas o papel impreso y pintarlo manualmente sobre un fondo de color. Respecto al brazo noble de la ciudad, hay que destacar, entre otros muchos ejemplos posibles, las dos cajoneras de charol con papel, es decir, trabajadas con dicha técnica, al morir, José Bautista Pastor y Sentís tenía en su vivienda, o una cómoda de madera con diferentes figuras de papel con cuatro cajones grandes y cuatro pequeños propiedad de la dama $\mathrm{M}^{\mathrm{a}}$ Francesca Corazones, casada con el noble señor de Olmera ${ }^{19}$. 


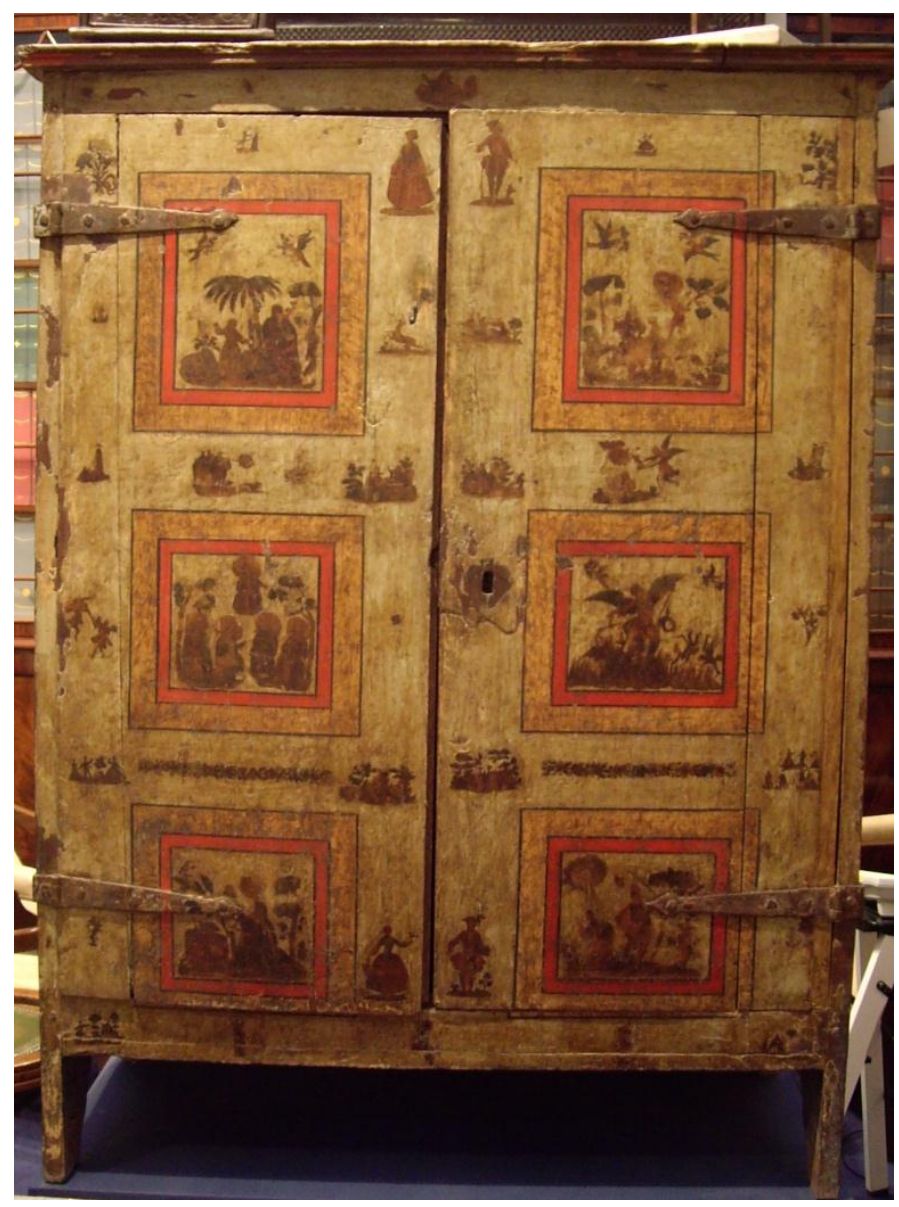

Fig. 5. Armario decorado con laca povera. Colección particular.

La aproximación a los artefactos suntuosos que vestían las casas principales de la ciudad no estaría completa si no se abordaran las manufacturas fabricadas en la ciudad. Abandonando los mercados exteriores, los talleres de la ciudad ofrecían, siguiendo las corrientes imperantes, un buen surtido de artículos tal y como lo demuestran los gastos hechos, por ejemplo, por el Duque de Sessa. Para alejarnos de la confección de un catálogo de tipologías mobiliario de las compras realizadas por Don José de Guzmán Vélez, Ladrón de Guebara y Tassis, Enriquez, Porras, marqués de Montealegre, Quintana, conde de Oñate, Villamediana, Camporreal, duque de Soma y Baena, conde de Cabra y Palamós, hidalgo de cámara del monarca, también conocido popularmente como duque de Sessa, quisiéramos abordar un único encargo como paradigma de lo que fue la adquisición de un artefacto lujoso en los talleres de la ciudad, que demuestran el nivel artístico de los mismos. Así pues de la larga lista de muebles comprados - en el campo del menaje doméstico encomendó varios artículos, especialmente camas y asientos, además de piezas de ropa para la capilla y tapicerías por el mobiliario - pensamos que la confección de la cama ala imperial, que fue entregada en Madrid en 1755 es sintomática de lo que se ha ido exponiendo hasta el momento. 
Este encargo permite seguir la dinámica de trabajo en la construcción de una pieza suntuosa. Del encargo a la entrega.

Lo primero que sorprende es la gran cantidad de artesanos que participaron en su construcción puesto que, además del carpintero, intervinieron el tallista, el dorador y una serie de oficios vinculados al campo del textil, muchos de los cuales tardaron más de un año en realizar el trabajo, que había comenzado alrededor de 1754. Desgraciadamente, desconocemos cuando el taller de Joan Llausàs recibió el encargo de confeccionar la estructura de madera de nogal y abedul, que posteriormente Carles Grau, tallista, y Joan Tubau, dorador, ornamentaron, pero, en cambio, disponemos de información sobre los jornales necesarios para terminar las tareas de carpintería y escultura, así como el personal que trabajó en ella. Respecto a los carpinteros, Llausàs mandó la realización de la pieza a un maestro carpintero, un joven oficial y un aprendiz que dedicaron treinta, sesenta $\mathrm{y}$ cinco $\mathrm{y}$ treinta $\mathrm{y}$ siete jornales $\mathrm{y}$ medio, respectivamente. En el trabajo de talla que ornamenta la cama, Carles Grau invirtió un número de horas considerablemente superior, pues para la realización del pabellón y los pies de la cama se emplearon ciento diecinueve días de trabajo de oficial y cincuenta dos días de maestro escultor. Desafortunadamente desconocemos las jornadas de trabajo empleadas por el dorador Joan Tubau, en la doradura y el barnizado del mueble, aunque conocemos que trabajo a la cama a la manera "chinesca", es decir que opto por imitar la técnica de las lacas con ornamentación de tipo oriental.

La cama se vistió con suntuosas telas que en parte fueron adquiridas en la tienda propiedad de Anton Gibert. Otras se adquirieron en la Real Fábrica de María Ángela y Juan Pablo Canales por el sastre Rafael Fuster ${ }^{20}$. En estos comercios de la ciudad se adquirieron el raso por la parte exterior y sarga de seda para el interior de la cama, ya que el resto de los materiales textiles empleados fueron adquiridos por el maestro bordador Joan Bautista Muns quien se trasladó acompañado de un aprendiz, hasta Lyon durante un mes para comprar pelfilles para bordar la pieza. Los gastos que el duque de Sessa pagó y el tiempo que Muns empleó en la confección del pedido son, cuando menos, remarcables. Las compras de Muns en Lyon - hilos de diferentes colores, seda, papel, llaves y bastidores nuevos - fueron enviadas a la ciudad tiempo después por mar, pagando a la entrada del puerto barcelonés sus correspondientes impuestos. No obstante, los jornales y el número de bordadores empleados en la tarea son aún más relevantes, ya que participaron treinta y tres individuos. Por último, tampoco podemos omitir el trabajo del sastre Onofre Barnola, que cosió las diferentes prendas y cortinas de la cama, así como el trabajo del galonero Joan Torras, que dispuso de franjas, cordones y borlas a la suntuosa cama. En este último caso, la carta de pago preveía el traslado de un operario a Madrid para componer los adornos que fueran necesarios. 
Es imposible negar, con lo que se acaba de apuntar, la importancia del encargo a pesar de no conservar ninguna imagen. Afortunadamente, las trazas de muebles y de carpintería de blanco presentadas por los carpinteros y escultores en el pleito que mantenían para determinar sus competencias profesionales nos permiten conocer de primera mano cómo eran muchos de los artefactos citados en la documentación y ayudan a dibujar mejor al lector estas escenografías del habitar $^{21}$. (Fig. 6)

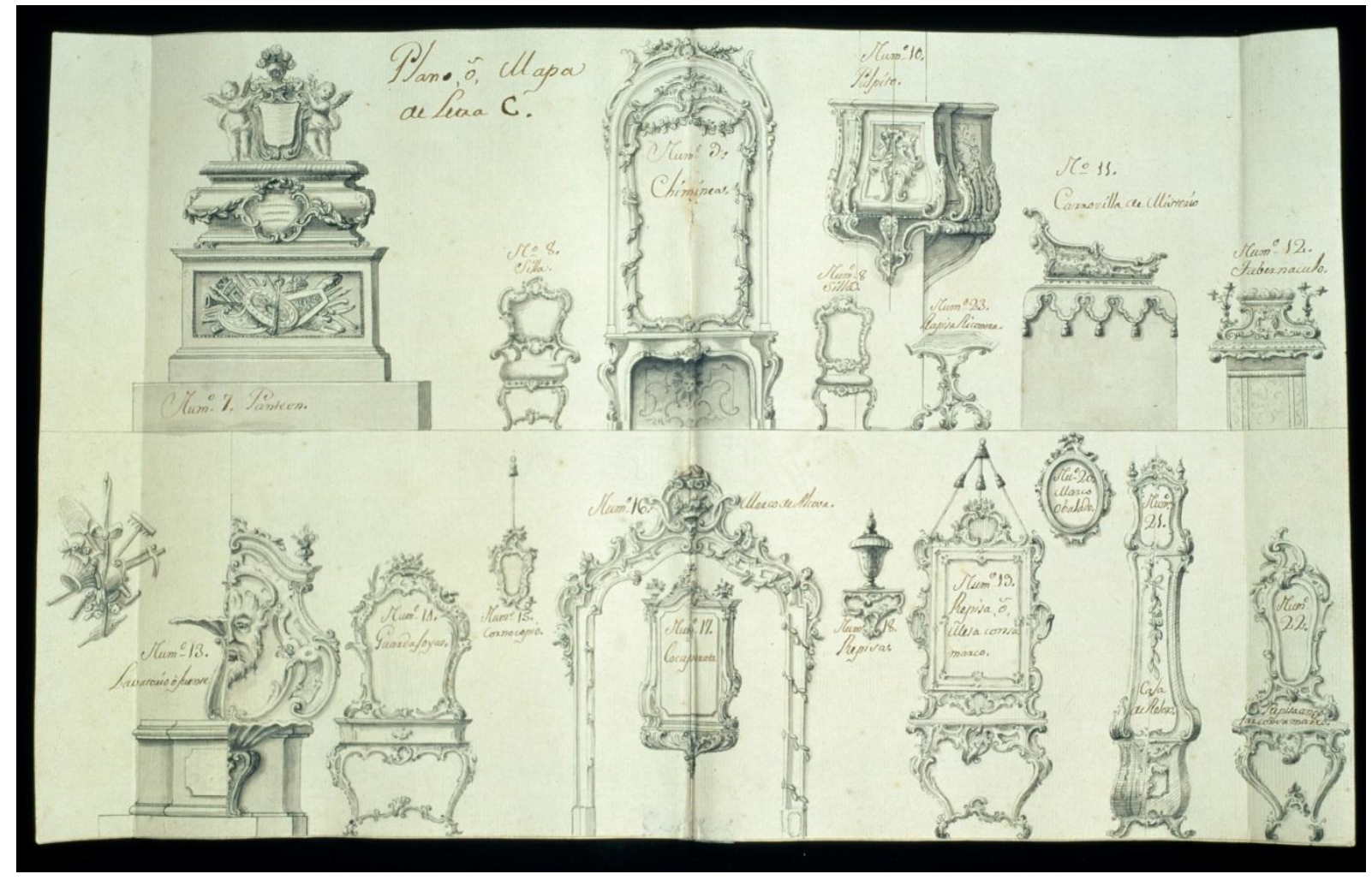

Fig. 6. Trazas de muebles presentadas en el pleito entre escultores y carpinteros. España. Ministerio de Cultura. Archivo de la Corona de Aragón, Col.MP-15

Entre los muebles presentados, por unos y otros, quisiéramos destacar la evolución en cuanto las camas, los guarda joyas que acaban transformándose en lligadors, así como los diferentes asientos, donde destaca el modelo conocido como poltrona y las sillas de clara influencia inglesa además del canapé. En cuanto al trabajo de carpintería de lo blanco no podemos olvidar mencionar los diferentes modelos de puertas, marcos así como la biblioteca empotrada en la pared y la chimenea, presentada por los carpinteros. (Fig. 7) 


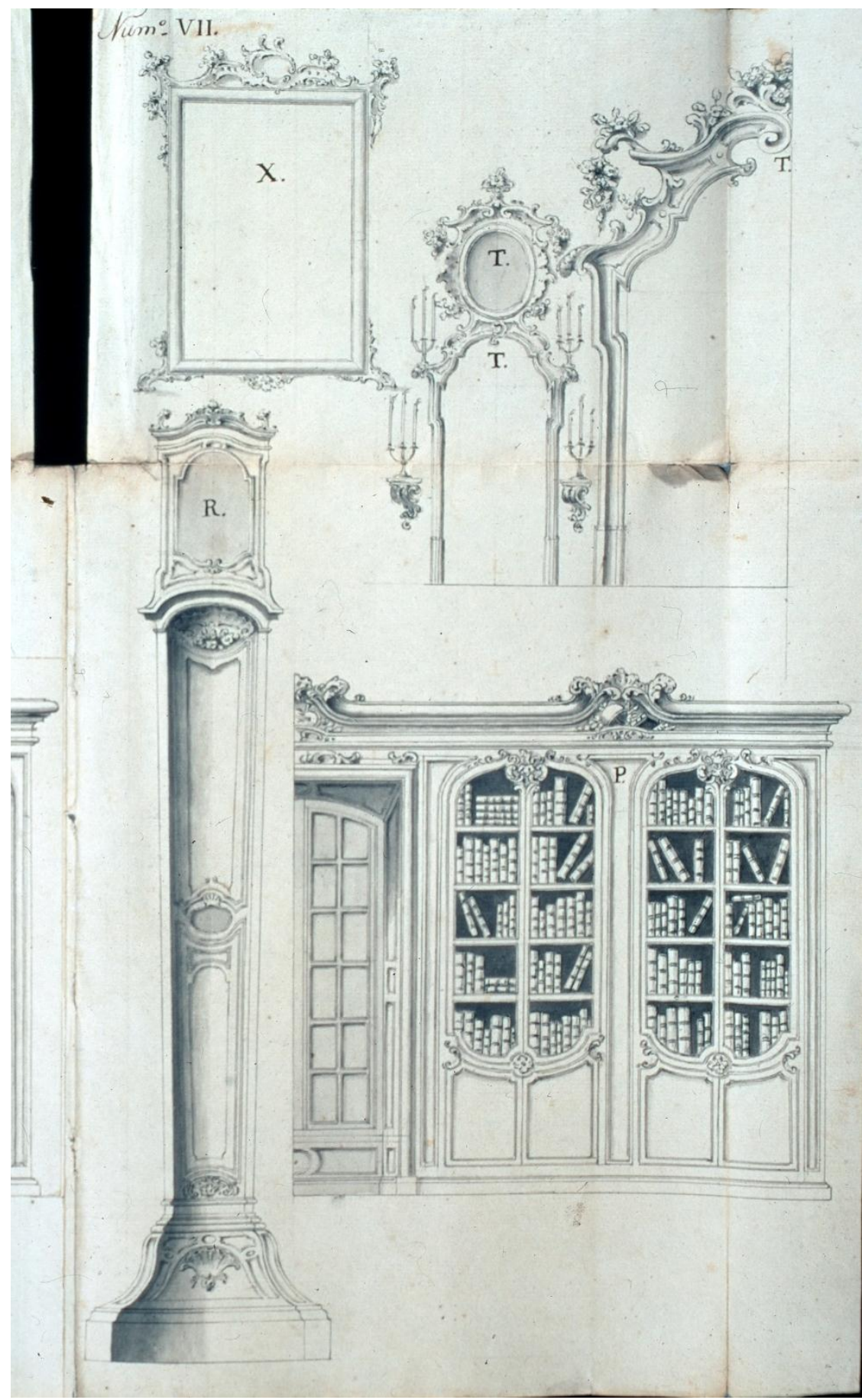

Fig, 7. Traza librería, espejo, carpintería de blanco. España. Ministerio de Cultura. Archivo de la Corona de Aragón, Col.MP-15.

Sin embargo en el conjunto de trazas también aparecen otros elementos como altares, frontales de órgano, tribunas o incluso un carruaje. Y es que la posesión de un carruaje fue uno de los signos más visibles de prestigio y diferenciación entre las clases adineradas de la ciudad, ya que fue uno de los 
signos más evidentes de la capacidad económica de un linaje. Tal y como apuntan determinados autores pocas veces en la historia aparece un ingenio con tanta capacidad para la representación de la jerarquía y la exhibición del lujo y el poder $^{22}$.

De alguna manera, aquellos que eran dueños de una carroza o carruaje marcaban una frontera con aquellos otros que no podían permitírsela, ya que alcanzaban la posibilidad de una mayor libertad de movimiento. Por eso no es de extrañar que en cualquier ceremonia familiar importante los miembros de la nobleza que no tenían optaran por alquilarlo durante algunas horas o días. Y no olvidemos que la propiedad de un rico carruaje formaba parte de la escenografía cotidiana de muchas estampas familiares y ciudadanas. (Fig. 8) La aparición de un lujoso coche de caballos por las calles de Barcelona indicaba a los peatones el desplazamiento de una $\mathrm{u}$ otra familia o personaje importante dentro de este pequeña sociedad. Martin Zeller, en su libro Hispaniae et Lusitaniae Itinerarium, publicado en 1637, recoge que cualquier persona de importancia se movía en caballo o coche de caballos. Apuntaba, además, que en Barcelona cada noche cuando el tiempo era propicio la gente salía a pasar con carruaje junto al mar, participando en ello más de cien $\operatorname{coches}^{23}$. Si bien sea conveniente ser prudentes respecto a la cantidad de carruajes existentes según el alemán en la ciudad, no deja de ser interesante su comentario pues demuestra el gusto por la ostentación y exhibición a través de su uso.

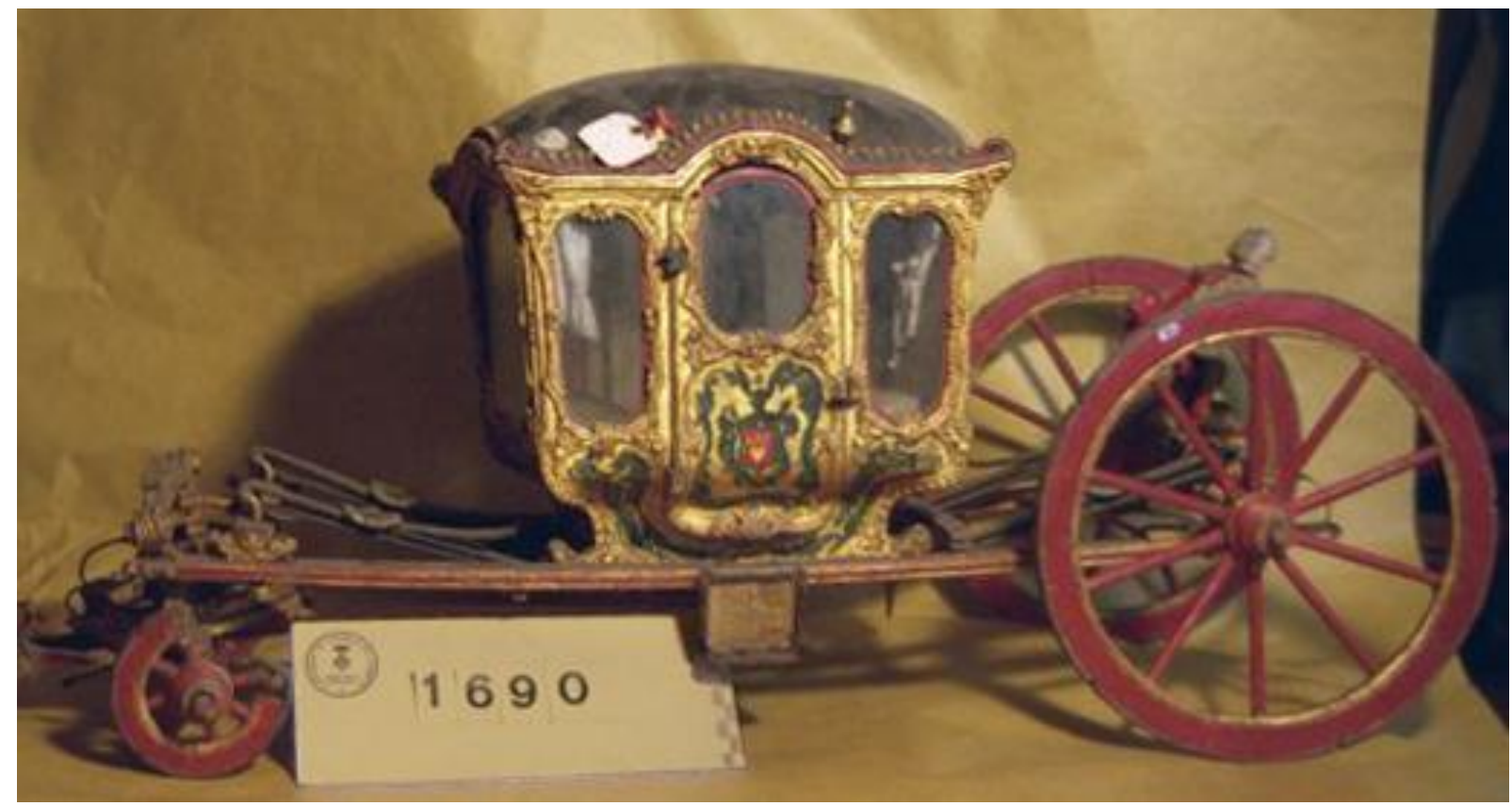

Fig. 8. Carruaje de juguete. Siglo XVIII. Museu Palau Mercader/Ajuntament de Cornellà de Llobregat.

La importancia social que adquirió el carruaje entre las clases acomodadas como signo de fastuosidad y riqueza también queda evidenciada con las cinco disposiciones que aparecían en la pragmática ordenada por Felipe $\mathrm{V}$, vigente a mediados de la centuria, donde se disponía, entre otras restricciones, que no 
estaba permitido pintar ni platear los coches, carrozas, calesas o cualquier modelo de vehículo de tiro, permitiendo exclusivamente un único color o los veteados a manera de falsos mármoles. Aunque habitualmente estaban ricamente pintados con escenas historiadas, marinas, bosques, flores, mascarones, la heráldica de los propietarios y perspectivas que se conjugaban con ricas tapicerías interiores ${ }^{24}$.

En definitiva, podemos decir que ningún acto, —moverse, vestirse, adquirir, recibir o invitar- llevado a cabo por la aristocracia del momento escapaba al hecho y deseo de mostrarse. Así la elección de los enseres domésticos, de un mueble, de los ropajes o la ornamentación del espacio privado, de manera consciente o inconsciente, siguiendo modas o gustos, fueron la herramienta perfecta para crear una determinada imagen pues hablaban calladamente de su propietario o poseedor. Y en este entramado el lujo jugó un papel fundamental tal y como se ha venido demostrando. Como apuntó Baltasar Gracián "No ay velleza sin Ayuda, ni perfección que no dé en bárbara sin el realce del artificio: a lo malo socorre y lo bueno lo perfecciona. (...) Todo hombre sabe a tosco sin el artificio, y ha menester pulirse en todo orden de perfección”25.

\section{NOTAS}

\footnotetext{
${ }^{1}$ El presente artículo parte de algunas de las aportaciones realizadas en nuestra tesis doctoral Cases Grans. Interiors nobles a Barcelona (1739-1761). Barcelona, Universitat de Barcelona, 2005.

${ }^{2}$ Existe una extensa bibliografía entorno al papel que juega el lujo en la configuración de la imagen. Destacar PIERROT, Philippe, Le luxe: une richesse entre faste et confort XVIIè-XIXè siècle, Paris, Éditions du Seuil, 1995 o el más reciente trabajo del historiador CARMAGNANI, Marcello, Las islas del lujo: productos exóticos, nuevos consumos y cultura económica europea 1650-1800, Madrid, Marcial Pons, 2012. En el ámbito catalán quisiéramos destacar el articulo de CALVERA, Anna, "Dins la bóta de diògenes: luxe, confort i benestar en la visió setcentista de la vida domèstica" en: http://tdd.elisava.net/coleccion/la-cultura-arquitectonica-el-discursdel-disseny-el-disseny-i-la-seva-historia/dins-la-bota-de-diogenes-luxe-confort-i-benestar-en-la-visio-setcentistade-la-vida-domestica-1

${ }^{3}$ SEMPERE GUARIÑOS, Juan, Historia del luxo y de las leyes suntuarias de España, Madrid, Imprenta Real, 1788.

${ }^{4}$ ROMÀ ROSSELL, Francisco, Las senyales de la felicidad en España, Barcelona, Altafulla, 1989 [1768].

${ }^{5}$ SEMPERE GUARIÑOS, Cit. 1, pp. 12-13.

${ }^{6}$ Ibídem, pp. 109. El comentario forma parte de la obra Conversación de Monarquías.

${ }^{7}$ Arxiu Històric de la Ciutat de Barcelona (A.H.C.B), Fons Municipal. Al·legacionsJurídiques,"Bans, Edictes i Pregons. 1718-1779", Año 1729.

${ }^{8}$ En Barcelona las residencias de la aristocracia se denominan cases grans, reservándose el termino de palacio para aquellas viviendas de tipo oficial. Véase CREIXELL, Rosa, "L'art de la distribució”, Op. Cita 1, pág. 171

${ }^{9}$ BAILS, Benito, Elementos de matemáticas. Tratado de arquitectura civil, Madrid, Imprenta Ibarra, 1783.

10 CABRÉ, Dolors, "Comerçatlàntic i mediterrani al segle XVI: Canàries, Portugal, Barcelona" en: XIII Congrésd'història de la Corona d'Aragó, Palma de Mallorca, Comunicacions III, 1990, pp. 109-116.

11 El noble Anton de Sunyer Massip i de Belloc , casado con Maria Bastero, murió en 1754. Su vivienda puede considerarse lujosa si atendemos que presentaba capilla y comedor, además de estrado y 24 habitaciones para distintos usos.
} 

${ }^{12}$ María Rocabertí i Descatllar casada con el noble Joan Cruïlles-Sitjar y de Sarriera, era hija del marqués de
Argensola, estaba emparentada con distinguidas casas de la aristocracia catalana como el marquesado de
Castellbell o los barones de St. Esteve. El matrimonio vivía en la calle Moncada, una de las principales arterias
aristocráticas de la ciudad.

13 Arxiu Històric de Protocols de Barcelona (A.H.P.B.), Not. Campllonch, Fèlix. Liberterciuscapitulorummatrimonialium, conconrdiarum, inventariorum et auccionum. 1756-1758, Año 1757, fol. 270r.

${ }^{14}$ Biblioteca de Catalunya (B.C), Fons Baró de Castellet. Francesc Roig i Vives. "Comerç marítim. 1723-1736". [18/5].

15 A.H.P.B., Prats, Sebastià. Liber secundus capitulorum matrimonialium, concordiarum, societatum, inventariorum, auctionum, requisicionum, deliberacionum, compromissorum et aliorum diversorum. 1748-1751, Año 1750, fols. 295r-299v.

${ }^{16}$ A.H.P.B, Not. Plana Circuns, Joan Baptista. Liber primus inventariorum et encantuum. 1737-1751, Año 1743, inv. núm. 11, s/fol.

${ }^{17}$ B.C, Fons Baró de Castellet. Francesc Roig i Vives. "Comerç marítim. 1723-1736”. [18/5].

${ }^{18}$ A.H.P.B, Not. Claramunt Gavarró, Ignasi, Primum manuale inventariorum et encantuum. 1747-1767, Año 1766, fol. 346r.

${ }^{19}$ A.H.P.B., Not. Fontana, Josep Bonaventura, Liber primum invnetariorum et encantuum. 1751-1755, Año 1754, inv. núm. 32.

${ }^{20}$ A.H.P.B, Not. Rondó, Carles, Vigessimum septimum manuale instrumentorum, 1757-1758, Año 1758, fols. $423 \mathrm{v}-423 \mathrm{r}$.

${ }^{21}$ La cronología de este pleito hace referencia al periodo entre 1680 y 1773. En el largo proceso aparecen multitud de denuncias y causas, que pueden ser estudiadas como casos individuales o en su conjunto como parte de un problema más amplio. Las trazas presentadas las dimos a conocer por primera vez en el artículo "L'ofici de fuster en la Barcelona del set-cents. Noves aportacions documentals, noves mirades" en Locus amoenus, Núm. 9, Barcelona, Universitat Autònoma de Barcelona, 2008, págs. 229-247.

${ }^{22}$ Historia del carruaje en España, Madrid, Fomento de Construcciones y Contratas, 2005. La utilización del carruaje como signo de prestigio y el papel que ocuparon en las estrategias de representación ha sido abordado por Alejandro López en múltiples trabajos. Entre ellos destacamos LOPEZ, Alejandro, Poder, lujo y conflictos: Coches, carrozas y sillas de manos en la corte de los Austria, Madrid, Universidad Autónoma de Madrid, 2004.

${ }^{23}$ Ibídem, pág. 2.

${ }^{24}$ A.H.C.B, Fons Municipal. Al-legacionsjurídiques, "Bans, edictes, pregons", Pragmatica sancion que su magestad manda observar sobre trages y otras cosas y por su real resolucion se bolvio à publicar en este año 1729, Barcelona, Joseph Teixidó, 1729.

${ }^{25}$ GRACIÁN, Baltasar, Oráculo manual $i$ arte de prudencia, 12, Edición digital a partir de la edición de Huesca, Juan Nogués, 1647 y cotejada con la edición crítica de Emilio Blanco, Madrid, Cátedra, 1997.

Fecha de recepción: 3 de septiembre de 2015

Fecha de revisión: 28 de septiembre de 2015

Fecha de aceptación: 6 de octubre de 2015 